\title{
Ativos intangíveis e governança corporativa no mercado de capitais brasileiro
}

\author{
Intangible assets and corporate governance in the brazilian stock market
}

\section{Julio Henrique Machado}

Mestre em Ciências Contábeis e Atuariais pela PUC/SP

Especialista MBA Internacional em Auditoria, Controladoria e Finanças -

FUNDACE FEARP/USP e Bournville - Birmingham Inglaterra.

Professor da Libertas Faculdades Integradas de São Sebastião do Paraíso-MG

Endereço: Rua Geraldo Marcolini, 1.561 - Vl. Sta. Maria

CEP: 37.950-000 - São Sebastião do Paraíso/MG - Brasil

E-mail: cursojhm@bol.com.br

Telefones: (35) 8801-6004 ou (35) 3531-2572

\section{Rubens Famá}

Doutor e mestre em Administração pela FEA/USP

Professor do Programa de Pós-Graduação em Ciências Contábeis e Atuariais da PUC/SP

Rua Moraz, 656 - apto 5 - Vila Madalena

CEP: 05434-020 - São Paulo/SP - Brasil

E-mail: rFamá@usp.br

Telefone: (11) 38148152 


\title{
Resumo
}

O desenvolvimento constante do ambiente de negócios gerou dois elementos muito debatidos pela comunidade acadêmica: Ativos Intangíveis e Governança Corporativa. Como os referidos ativos são também provenientes da imagem da companhia no mercado, percebe-se então sua ligação com práticas de Governança Corporativa. Assim, o presente trabalho, de natureza exploratória-descritiva, tem o objetivo de verificar o nível médio de intangibilidade das companhias listadas na BM\&FBOVESPA nos segmentos diferenciados de Governança Corporativa. Foi estudado o período de 2002 a 2007 tendo o índice de intangibilidade como variável de pesquisa. Observou-se que as companhias que aderem ao mais alto nível de Governança Corporativa da BM\&FBOVESPA, o Novo Mercado, apresentaram em média maior intangibilidade. O Nível 2 e o Nível 1 não apresentaram diferença significativa na variável estudada, mas possuem um nível médio de intangibilidade menor do que o grupo formado pelas companhias que não aderem aos níveis mais altos de governança.

Palavras-chave: Ativo intangível. Governança corporativa. Mercado de capitais.

\begin{abstract}
The constant development of the business environment has generated two very debated elements by the academic community: Intangible Assets and Corporate Governance. As the referred assets are also proceeding from the image of a company in the market, perceives then the linking with the Corporate Governance skills. Thus, the present work, of explore-description nature, has the objective to verify if the average level of intangibility of the company listed in the BM\&FBOVESPA follows the differentiated level of governance which is submitted. The period between 2002 and 2007 were studied, having the index of intangibility as variable of research. It was observed that the company that adheres to the highest level of Corporate Governance of the BM\&FBOVESPA, the New Market, had presented bigger level of intangibility on average. The Level 2 and Level 1 had not presented significant difference in the studied variable, but they possess an average level of intangibility smaller than the group formed by the companies that do not adhere to the differentiated levels of governance.
\end{abstract}

Keywords: Intangible asset. Corporate governance. Stock market.

\section{Introdução}

Aprofundar em teorias econômicas e modelos de gestão implica estudar o contexto em que tais elementos foram criados. Conhecer o histórico de desenvolvimento econômico das nações auxilia no entendimento do ambiente empresarial vivido nos dias de hoje. O desenvolvimento da economia de mercado, voltada para o pleno emprego de capital, faz com que as técnicas de gestão empresarial sejam reformuladas e aprimoradas. Entre os fatores determinantes da continuidade das companhias, podem ser destacados os ativos intangíveis e as práticas de governança corporativa, como elementos que passaram a ser estudados pela comunidade acadêmica e pelas grandes corporações a partir da década de 1970 .

As primeiras empresas negociadas publicamente, surgidas na era industrial, extraíam dos ativos físicos a maior parte do seu valor. Esses gigantes corporativos do passado, como General Motors, Standard Oil e AT\&T, exemplificados por Damodaran (2004), possuíam terrenos, propriedades e fábricas que se prestavam 
facilmente às mensurações contábeis.

Durante anos após a Segunda Guerra Mundial, o sucesso das empresas dependia de um contato estreito com a elite política, comercial e financeira. Estes laços eram mais importantes do que visão estratégica e excelência em gestão empresarial.

Mas em meados da década de 1970 e início da década de 1980, este ambiente começou a mudar. A liberação de taxas de cambio, o início de tendências de privatizações ao redor do mundo, entre outros motivos, impulsionou o desenvolvimento da economia de mercado. Esta nova realidade fez com que as empresas passassem a conviver com maior concorrência, fazendo surgir a necessidade de diferenciação. Esta necessidade originou o surgimento de marcas e muitas companhias passaram a investir pesadamente em treinamento, pesquisas e desenvolvimento.

Neste período, surgiu uma nova geração de empresas, como Coca-Cola, Pfizer, Microsoft e outras que obtêm o principal do seu valor a partir de ativos sem nenhuma forma física. Esses ativos intangíveis variam entre as empresas, podendo ser respectivamente para os exemplos citados, marca, patentes e especialização tecnológica (DAMODARAN, 2004).

Aliado ao desenvolvimento econômico já descrito ocorreu outra mudança notável no mundo corporativo: a dispersão do capital e do controle das companhias. A distinção entre propriedade e gestão, como conseqüência da evolução constante das sociedades capitalistas, passou a fazer parte do cotidiano das organizações. Esta distinção torna-se ainda mais evidente conforme a necessidade de captação de recursos e alta exposição no mercado. Entretanto, manter propriedade e gestão em grupos diferentes conduz aos problemas de agencia e a assimetria informacional. Para minimizar estes problemas surgiram as práticas de Governança Corporativa, a qual juntamente com os ativos intangíveis, constitui-se no foco do presente trabalho.

Enfrentar ambientes altamente competitivos faz com que as companhias dediquem esforços para gerir da melhor forma possível seus ativos intangíveis. Desse modo, espera-se que a implantação de práticas de Governança Corporativa auxilie na geração de ativos intangíveis, conduzindo à proposição de que existe forte ligação entre ambos.

Considerando que os ativos intangíveis são elementos sem substancia física que geram benefícios futuros, e que Governança Corporativa constitui-se de práticas que melhoram o relacionamento da empresa com os stakeholders, conduzindo uma boa imagem da empresa no mercado, o trabalho desenvolveu-se na tentativa de responder à seguinte questão: As melhores práticas de Governança Corporativa são elementos determinantes na geração de ativos intangíveis no Mercado de Capitais Brasileiro? 
Conforme o referencial teórico pesquisado, os Níveis Diferenciados de Governança Corporativa da BM\&FBOVESPA (Bolsa de Valores de São Paulo) apresentam exigências específicas a serem cumpridas pelas companhias que os seguem. Quanto maior o nível de governança, maiores são as exigências. Esta consideração conduziu a seguinte hipótese a ser testada: Quanto mais alto o nível de governança, maior o nível de intangibilidade.

Pode-se sumarizar a hipótese da seguinte maneira:

$\mathrm{H}: \mu$ Intang NM $>\mu$ Intang N2 $>\mu$ Intang N1 $>\mu$ Intang SA

Neste contexto o objetivo do trabalho foi verificar a intangibilidade das empresas brasileiras de capital aberto listadas na BM\&FBOVESPA, no período de 2002 a 2007 conforme os níveis diferenciados de Governança Corporativa aos quais submetem-se.

De acordo com as definições de Ativos intangíveis e Governança Corporativa encontradas na literatura, bem como os resultados de pesquisas científicas, entende-se que são elementos que possuem forte ligação. Devido a sua importância e relevância, são necessárias pesquisas na tentativa de melhor entende-los.

Os ativos intangíveis tem alcançado proporção cada vez maior no valor das empresas. Segundo Lev (2001), o índice valor de mercado/valor contábil (market-to-book ratio) das empresas listadas na S\&P 500 subiu de 1, no início dos anos 1980, para 6, em 2001. Kayo, Teh e Basso (2006) interpretam que essa valorização denota, em grande parte, a crescente importância da geração de riqueza propiciada pelos ativos intangíveis.

A Governança Corporativa, por sua vez, reduz o risco e gera melhor precificação das ações, motivando novas aberturas de capital por parte das empresas. Se é correto afirmar que quanto mais rígida a regulamentação de um país quanto a proteção aos direitos dos acionistas, mais forte é o seu mercado acionário, então percebe-se que o fortalecimento deste mercado, através de práticas de governança, contribui também com o desenvolvimento da economia do país. Neste contexto, Andrade e Rossetti (2009) lembram que organizações multilaterais, como a Organização para Cooperação e Desenvolvimento Econômico, o Fundo Monetário Internacional e o Banco Mundial, além de outras instituições internacionais, como o G8, vêem nos princípios de Governança Corporativa uma base sólida para o crescimento econômico e para a integração global de mercados.

Se as práticas de Governança Corporativa contribuem com a melhoria da imagem de uma organização, espera-se que estas sejam importantes elementos formadores de ativos intangíveis, o que demonstra a necessidade de pesquisas neste âmbito.

Este artigo traz importantes contribuições ao estudo de finanças e contabilidade por demonstrar, através de pesquisa empírica, possíveis relações existentes entre os objetos de estudo. Demonstrar cientificamente o quão importante são 
os ativos intangíveis faz com que órgãos normatizadores em matéria contábil continuem dedicando esforços na tentativa de estabelecer os melhores modos de mensuração, reconhecimento e evidenciação desse grupo.

\section{Referencial Teórico}

\subsection{Ativo Intangivel}

Estudar ativos intangíveis significa ingressar em uma das áreas mais complexas e desafiadoras de contabilidade e finanças empresariais. Esta complexidade deve-se às dificuldades de identificação, definição, incertezas na mensuração e estimação de suas vidas úteis. Para o aprofundamento em intangível, tido por muitos autores como um dos principais ativos geradores de benefícios, faz-se necessário relembrar as definições de ativo.

Canning (1929) foi um dos primeiros a tentar definir os elementos patrimoniais. De forma abrangente definiu um ativo como qualquer serviço futuro, em termos monetários cujos direitos pertencem legal ou justamente a alguma pessoa ou conjunto de pessoas. Hendriksen e Van Breda (1999) definem ativos, mais tecnicamente, como potenciais de fluxos de serviço ou direitos a benefícios futuros sob o controle de uma organização. Kam (1990) sumariza os componentes essenciais dos ativos: proporcionar benefícios econômicos futuros, obtido e controlado pela empresa, resultante de transações e eventos passados.

Uma vez definidos os ativos, é preciso aprofundar na verificação de sua existência física. Como afirma Damodaran (2004), faz parte da natureza humana estabelecer uma distinção entre os ativos que pode-se e os que não se pode ver e sentir, e sente-se um pouco mais de segurança com o primeiro grupo. A dificuldade de uma definição formal para o grupo dos intangíveis é enfatizada por Martins (1972), ao alertar que a definição de ativo intangível como aquele que não possui existência física ou que não pode ser tocado é simplista e incompleta. $\mathrm{O}$ autor exemplifica que Investimentos, Duplicatas a Receber e Depósitos Bancários são todos direitos, mas apesar da falta de existência corpórea, são considerados tangíveis.

Para Hendriksen e Van Breda (1999) o primeiro passo no estudo de um intangível é enquadrá-lo na definição de ativo. Posteriormente, verificam-se os ativos que carecem de substancia.

Lev (2001) define ativo intangível como um direito a benefícios futuros que não possui corpo físico, que é criado pela inovação, por práticas organizacionais e pelos recursos humanos. Acrescenta o autor que os ativos intangíveis interagem com os ativos tangíveis na criação de valor corporativo e no crescimento econômico. Esta interação entre ativos tangíveis e intangíveis também é citada 
por Kayo e Famá (2004, p. 175) como elemento que contribui para a formação do valor das empresas: "O capital intangível bem empregado pode fazer o capital tangível render muito mais e, assim, conjuntamente, maximizar o valor da empresa e a riqueza do acionista".

Ao interpretar as afirmações acima, pode-se definir ativo intangível como ativo de natureza permanente, sem existência física que, em conjunto com os ativos tangíveis, seja capaz de produzir benefícios futuros.

Iudícibus (2004) e Perez e Famá (2006) exemplificam os intangíveis: goodwill, gastos de organização, marcas e patentes, direitos autorais, franquias, custos de desenvolvimento de softwares, bancos de dados, concessões públicas, direitos de exploração e operação, carteira fiel de clientes, etc. Estes ativos, quando bem geridos, tornam-se fontes de vantagem competitiva sustentável para as empresas, proporcionando ganhos crescentes de escala: quanto maior a rede de usuários, maior o benefício para todos (HOSS; ROJO; GRAPEGGIA, 2010).

Para contribuir com uma melhor compreensão, Kayo (2002) classifica os ativos intangíveis conforme o Quadro 1:

Quadro 1 - Uma Proposta de Classificação dos Ativos Intangíveis

\begin{tabular}{|c|l|}
\hline Tipo de Intangível & \multicolumn{1}{|c|}{ Principais Componentes } \\
\hline Ativos Humanos & $\begin{array}{l}\text { - conhecimento, talento, capacidade, habilidade e experiência dos } \\
\text { empregados; administraçã superior ou empregados-chave; } \\
\text { treinamento e desenvolvimento; entre outros. }\end{array}$ \\
\hline Ativos de Inovação & $\begin{array}{l}\text { - pesquisa desenvolvimento; patentes; fórmulas secretas; know- } \\
\text { how tecnológico; entre outros. }\end{array}$ \\
\hline Ativos Estruturais & $\begin{array}{l}\text { - processos; software proprietários; bancos de dados; sistemas de } \\
\text { informação; sistemas administrativos; inteligência de mercado; } \\
\text { canais de mercado; entre outros. }\end{array}$ \\
\hline $\begin{array}{c}\text { Ativos de } \\
\text { Relacionamento } \\
\text { (com públicos } \\
\text { estratégicos) }\end{array}$ & $\begin{array}{l}\text { - marcas; logos; trademarks; direitos autorais (de obras literárias, de } \\
\text { software, etc); contratos com clientes, fornecedores, etc; contratos de } \\
\text { licenciamento, franquias, etc; direitos de exploração mineral, de } \\
\text { água, etc; entre outros. }\end{array}$ \\
\hline
\end{tabular}

Fonte: Kayo (2002, p. 19).

É comum a aceitação de que os intangíveis proporcionam maior valor econômico aos empreendimentos. Mas é importante ressaltar que exercem papéis diferenciados em cada empresa, dependendo de uma série de fatores, como por exemplo, características do setor de atuação e estratégias implantadas.

\subsection{Governança Corporativa}

Jensen e Meckling (1976), em artigo seminal, propuseram uma teoria centrada na integração de elementos de agencia, direitos de propriedade e finanças. Dessa forma, as pesquisas relacionadas à governança corporativa começaram a ter como foco principal o conflito entre agente (administrador) e principal (acionista) e também a divisão de ownership (poder) e control (controle). Os autores, precursores da teoria de agencia, afirmam que o conflito de agencia ocorre quando há delegacão de poder decisório e quando as decisões nem sempre são tomadas 
no melhor interesse de quem delega, por negligencia, incompetência ou má-fé de quem decidiu. Iudícibus e Lopes (2004) interpretam este fato descrevendo que o conflito de agencia surge quando os agentes ligados à empresa possuem interesses contrastantes e ao colocar seus interesses pessoais em primeiro lugar acabam por prejudicar o andamento da organização.

Outro aspecto considerado pela teoria de finanças, proveniente da distinção entre propriedade e gestão é a assimetria informacional, a qual refere-se a diferenças em informações disponíveis aos administradores e aos acionistas. Brigham, Gapenski e Ehrhardt (2001) afirmam que os administradores têm, com freqüência, melhores informações do que os investidores externos. Devido a estrutura hierárquica, a assimetria informacional é um fato. Os acionistas estão em desvantagem informacional em relação aos altos executivos da empresa, que por sua vez não possuem o mesmo nível informacional dos subordinados.

Conflitos de agencia e assimetria informacional são dois elementos que, segundo Iudícibus e Lopes (2004), permeiam a atividade das organizações modernas de forma profunda. Ressaltam que não se pode ambicionar a um estudo sério das organizações modernas sem a consideração desses dois fatores, que estão intimamente ligados. Estes aumentam o grau de incerteza para o investimento em uma companhia, o que significa maior nível de risco, elevando o custo de capital.

Neste contexto, nasce a Governança Corporativa, constituindo-se de mecanismos alternativos a serem adotados para evitar que os acionistas sejam expropriados de seus recursos pelos administradores e manter a boa relação da empresa com seus stakeholders (JESUS; ALBERTON, 2007; GONÇALVES et al., 2008). Estes mecanismos fazem com que a Governança Corporativa atue como redutora de assimetria informacional e custo de capital. Para Malacrida e Yamamoto (2006), esta redução acontece como resultado da divulgação contábil, a qual, para os autores, constitui-se um dos principais pilares de Governança Corporativa.

Montgomery e Kaufman (2003) dissertam que o equilíbrio do poder corporativo depende de três ancoras cruciais que demandam fundamental interação: propriedade, conselho de administração e diretoria executiva. A eficácia do processo de governança é definida pelas relações entre os três fatores destacados, evitando a passividade de qualquer um deles.

Considerando a relação entre os grupos envolvidos nas atividades empresariais, O IBGC (2010) define a Governança Corporativa da seguinte maneira:

O sistema pelo qual as sociedades são dirigidas e monitoradas, envolvendo os relacionamentos entre Acionistas/Cotistas, Conselho de Administração, Diretoria, Auditoria Independente e Conselho Fiscal. As boas práticas de Governança Corporativa têm a finalidade 
de aumentar o valor da sociedade, facilitar seu acesso ao capital e contribuir para a sua perenidade.

Esta definição é resumida por Andrade e Rossetti (2009) como um conjunto de “(...) princípios éticos aplicados na condução dos negócios." (ANDRADE; ROSSETTI, 2009, p. 26). Descrevem também os valores enfatizados pelas práticas de governança através de quatro aspectos: (1) compliance (conformidade legal); (2) accountability (prestação responsável de contas); (3) disclosure (transparência); e (4) fairness (senso de justiça).

O conceito dado pelo IBGC (2010) aliado aos grupos elencados por Andrade e Rossetti (2009) deixa claro que a Governança Corporativa constitui-se nos procedimentos saudáveis de interação entre a empresa e os diversos stakeholders, contribuindo com a continuidade. Esses procedimentos serão mais desenvolvidos conforme o ambiente legal e financeiro onde a empresa opera e reporta.

No caso do mercado de capitais brasileiro, Bertucci, Bernardes e Brandão (2006) descrevem que o desenvolvimento destas práticas ocorre em função da necessidade de corresponder às novas condições mundiais, por parte das companhias. Acrescentam que a aderência do modelo de governança praticado no país às condições do macroambiente global depende do alinhamento da estratégia econômica nacional aos traços dominantes da economia mundial e também do grau de internacionalização das corporações que operam no país. Como exemplo, Silva (2004) cita a reestruturação societária provocada pelas privatizações e a entrada de novos sócios nas empresas do setor privado, principalmente estrangeiros e investidores institucionais. Esta reestruturação tem mudado a relação entre acionistas majoritários, minoritários e administradores no Brasil.

Visando suprir a necessidade de aplicação de melhores práticas de governança, a Bolsa de Valores de São Paulo criou, em dezembro de 2000, os Níveis Diferenciados de Governança, proporcionando um ambiente de negociação que estimulasse o interesse dos investidores e a valorização das companhias. As diferenças entre os segmentos estão elencadas no Quadro 2:

Quadro 2 - Níveis diferenciados de Governança Corporativa da BM\&FBOVESPA

\begin{tabular}{|c|c|c|c|c|}
\hline & Novo Mercado & Nível 2 & Nível 1 & Tradicional \\
\hline Free float mínimo & $25 \%$ & $25 \%$ & $25 \%$ & Não há regra \\
\hline $\begin{array}{l}\text { Características das } \\
\text { ações emitidas }\end{array}$ & Somente ações ON & $\begin{array}{l}\text { Ações ON e PN (e } \\
\text { direitos adicionais) }\end{array}$ & Ações ON e PN & Ações ON e PN \\
\hline $\begin{array}{l}\text { Conselho de } \\
\text { Administração }\end{array}$ & $\begin{array}{l}\text { Mínimo de cinco } \\
\text { membros, dos quais } \\
\text { pelo menos } 20 \% \\
\text { devem ser } \\
\text { independentes }\end{array}$ & $\begin{array}{l}\text { Mínimo de cinco } \\
\text { membros, dos quais } \\
\text { pelo menos } 20 \% \\
\text { devem ser } \\
\text { independentes }\end{array}$ & $\begin{array}{l}\text { Mínimo de três } \\
\text { membros } \\
\text { (conforme } \\
\text { legislação) }\end{array}$ & $\begin{array}{c}\text { Mínimo de três } \\
\text { membros (conforme } \\
\text { legislação) }\end{array}$ \\
\hline $\begin{array}{c}\text { Demonstrações } \\
\text { Financeiras em } \\
\text { Padrão Internacional }\end{array}$ & US GAAP Ou IFRS & US GAAP ou IFRS & Facultativo & Facultativo \\
\hline $\begin{array}{c}\text { Concessão de Tag } \\
\text { Along }\end{array}$ & $\begin{array}{c}100 \% \text { para ações } \\
\text { ON }\end{array}$ & $\begin{array}{l}100 \% \text { para ações } \mathrm{ON} \\
\text { e } 80 \% \text { para ações } \mathrm{PN}\end{array}$ & $\begin{array}{c}80 \% \text { para ações ON } \\
\text { (conforme } \\
\text { legislação) }\end{array}$ & $\begin{array}{c}80 \% \text { para ações ON } \\
\text { (conforme } \\
\text { legislação) }\end{array}$ \\
\hline $\begin{array}{c}\text { Adoção da Câmara } \\
\text { de Arbitragem }\end{array}$ & Obrigatório & Obrigatório & Facultativo & Facultativo \\
\hline
\end{tabular}


Resumidamente, pode-se dizer que as empresas que aderem aos níveis 1 e 2 devem evitar a concentração acionária. O Nível 2 busca oferecer ao acionista minoritário direitos adicionais como forma de incentivar a participação de pequenos investidores. Apresenta também a necessidade de maior divulgação financeira, uma vez que o padrão contábil nacional não é o único a ser seguido. Este nível fornece aos investidores a segurança necessária na resolução de conflitos societários através da Câmara de Arbitragem do Mercado. O Novo Mercado constitui-se no conjunto de regras societárias mais rígidas que as existentes na atual legislação brasileira. As regras de listagem para o enquadramento no NM exigem que, além das práticas necessárias para o Nível 2, as empresas apresentem seu capital social dividido exclusivamente em ações ordinárias, seja, ações com direito a voto.

Os benefícios que a implantação destes segmentos podem proporcionar às empresas e aos investidores são assim descritos por Santana (2001):

- para as empresas: melhoria da imagem institucional, maior visibilidade, maior demanda pelas ações, valorização das ações e menor custo de capital;

- para os investidores: maior precisão na precificação das ações, melhoria do processo de fiscalização, maior segurança quanto aos direitos societários, redução de risco para o país, investimentos mais seguros, empresas mais fortes e competitivas e dinamização da economia.

\subsection{Pesquisas Recentes}

Os trabalhos acadêmicos recentes que relacionam-se com o propósito desta pesquisa foram descritos a seguir, por servirem de base conceitual para 0 desenvolvimento.

As pesquisas de Malacrida e Yamamoto (2006), Terra e Lima (2006) e Monte e outros (2010) estudaram a volatilidade do preço das ações conforme o nível de Governança Corporativa. A importância destas pesquisas reside no fato de que a volatilidade do preço dos ativos afeta o valor da empresa, e conseqüentemente o nível de intangibilidade.

Malacrida e Yamamoto (2006) pesquisaram a relação existente entre o nível de evidenciação das informações contábeis e a volatilidade do retorno das ações que compõem o Ibovespa. Rejeitaram a hipótese de que a volatilidade independe do nível de disclosure. As empresas que apresentam um maior nível de evidenciação possuem menor volatilidade média no preço das ações. O contrário ocorre com as empresas com menor nível de evidenciação. Considerando que a evidenciação está diretamente ligada com Governança Corporativa, entende-se que quanto maior o nível de governança, menor a volatilidade do preço. 
Terra e Lima (2006) investigaram se a divulgação das informações contidas nas demonstrações financeiras afeta igualmente as empresas em geral e aquelas com sinalizadores diferenciados de boas práticas de governança corporativa. Revelaram que os investidores reagem de forma diferenciada a alguns sinalizadores de boas práticas de governança corporativa das empresas, o que provoca influencia no valor da empresa. A pesquisa de Terra e Lima (2006) reforça que as iniciativas como os níveis diferenciados de governança constituem-se em importantes avanços rumo as evidenciações voluntárias, fazendo com que a contabilidade consolide sua relação com o mercado de capitais.

Monte e outros (2010) analisaram a composição, o risco e a persistência da volatilidade de três carteiras formadas por ativos de empresas que fazem parte dos três níveis de governança listadas na BM\&FBOVESPA. Confirmaram a hipótese de que quanto maior a transparência da empresa para com o mercado, menor a volatilidade do retorno das ações. O respaldo para esta confirmação deu-se através de testes estatísticos em regressão linear, os quais apresentaram evidencias de menor persistência de volatilidade das empresas do Novo Mercado. Neste segmento de governança, a relação entre boas práticas de Governança Corporativa e volatilidade dos ativos é negativa. Finalizaram o trabalho afirmando que a carteira formada por ativos de empresas do Novo Mercado é menos arriscada, comparativamente as formadas por ativos das empresas dos níveis 2 e 1 .

As pesquisas de Silva e Leal (2005), Lameira, Ness Junior e Soares (2007) e Perez e Famá (2006) foram voltadas ao estudo de desempenho econômico e valor.

Silva e Leal (2005) analisaram a relação entre a qualidade das práticas de governança corporativa e o valor e o desempenho econômico da firma. Utilizando como variáveis o indicador Q de Tobin e o ROA, respectivamente, verificaram através de análise em painel de dados que as companhias com boas práticas de governança têm um desempenho econômico significativamente superior, ocorrendo o mesmo com o valor. Corroborando a pesquisa de Silva e Leal (2005), Lameira, Ness Junior e Soares (2007) confirmaram a hipótese de que a melhoria de práticas de governança promove impacto no valor das companhias abertas. Adicionalmente, demonstraram que estas práticas influenciam o desempenho econômico das empresas.

Perez e Famá (2006) demonstraram que as companhias com elevados ativos intangíveis apresentam um desempenho econômico superior. Conforme o nível de intangibilidade das companhias, os autores as classificaram como tangívelintensivas e intangível-intensivas. Demonstraram que o último grupo gera maior valor econômico aos acionistas. Encerram o trabalho afirmando que os resultados foram tão claros no período analisado podendo inferir-se que os ativos tangíveis proveram às empresas apenas lucros normais e que a verdadeira criação de valor 
foi proporcionada pelos ativos intangíveis.

Observa-se que os trabalhos citados estudaram, mesmo que indiretamente, o valor de mercado das empresas. Este é influenciado pela volatilidade dos ativos, podendo-se inferir que o nível de intangibilidade das companhias também sofre influencia desta volatilidade. Assim, com base nos resultados das pesquisas aqui descritas, é correto afirmar que há uma relação de dependência entre as variáveis: governança corporativa, volatilidade, valor de mercado e intangibilidade.

\section{Metodologia da Pesquisa}

\subsection{Procedimentos Metodológicos}

O estudo segue a abordagem positivista, a qual utiliza subsídios para explicar e predizer determinados fenômenos. Baseando-se em observações da realidade, com dados empíricos processados quantitativamente, procura-se testar a hipótese delimitada para que se chegue a conclusões. Ou seja, não é foco da abordagem positiva demonstrar como "deveria ser", mas sim, aproximar-se ao máximo à realidade, demonstrando "como realmente é". Este caminho exige premissas alicerçadas em aparatos conceituais de natureza econômica.

$\mathrm{Na}$ tentativa de responder à pergunta de pesquisa, validando ou refutando a hipótese proposta, comparam-se os resultados encontrados com o referencial teórico. Assim, o método de pesquisa é descritivo, pois tenta descrever as características de determinado fenômeno de acordo com as relações entre variáveis. $\mathrm{E}$ também exploratório, pois busca tornar familiar um tema ainda pouco esclarecido, baseando-se em perspectivas acerca de teoria já existente.

\subsection{Amostragem e Coleta de Dados}

Utilizou-se o critério não-probabilístico de amostragem. A princípio, considerou-se uma população composta pelas 120 maiores companhias em termos de valor de mercado e volume negociado, excetuando instituições financeiras por apresentarem características distintas no que tange a alavancagem. Excluíram-se as empresas que não dispunham de dados completos e ações negociadas no período estudado, de 2002 a 2007 e também aquelas que apresentaram patrimônio líquido negativo. Assim, a amostra do trabalho totalizou 55 companhias, distribuídas conforme a adesão aos níveis diferenciados de Governança Corporativa da BM\&FBOVESPA, gerando assim, quatro grupos clusters, conforme o Quadro 3. O grupo formado pelas companhias que não aderem aos segmentos diferenciados foi denominado "Sem Adesão". 
Quadro 3 - Amostra

\begin{tabular}{|c|c|c|c|}
\hline $\begin{array}{l}\text { Novo Mercado } \\
\text { Cluster } 1 \text { - NM }\end{array}$ & $\begin{array}{c}\text { Nível } 2 \\
\text { Cluster } 2-\mathrm{N} 2\end{array}$ & $\begin{array}{c}\text { Nível 1 } \\
\text { Cluster 3- N1 }\end{array}$ & $\begin{array}{c}\text { Sem Adesão } \\
\text { Cluster } 4-\mathbf{S A}\end{array}$ \\
\hline $\begin{array}{c}\text { CCR Rodovias } \\
\text { Duratex } \\
\text { Eternit } \\
\text { Hering } \\
\text { Industrias Romi } \\
\text { Iochpe Maxion } \\
\text { Lojas Renner } \\
\text { Rossi } \\
\text { Sabesp } \\
\text { WEG }\end{array}$ & $\begin{array}{c}\text { Celesc } \\
\text { Marcopolo } \\
\text { Net - Embratel } \\
\text { Saraiva }\end{array}$ & $\begin{array}{c}\text { Alpargatas } \\
\text { Braskem } \\
\text { Cemig } \\
\text { Copel } \\
\text { Confab } \\
\text { CTEEP - Transm. } \\
\text { Paulista } \\
\text { Eletrobras } \\
\text { Gerdau } \\
\text { Gerdau Metalúrgica } \\
\text { Klabin } \\
\text { Paranapanema } \\
\text { Randon } \\
\text { Suzano } \\
\text { Ultrapar } \\
\text { Unipar } \\
\text { Usiminas } \\
\text { Vale }\end{array}$ & $\begin{array}{c}\text { Aços Villares } \\
\text { Ambev } \\
\text { Brasil Telecom } \\
\text { Coelce } \\
\text { Comgas } \\
\text { Estrela } \\
\text { Ferbasa } \\
\text { Forjas Taurus } \\
\text { Inepar } \\
\text { Kepler Weber } \\
\text { Lojas Americanas } \\
\text { Minupar } \\
\text { Petrobras } \\
\text { Panatlantica } \\
\text { Rimet } \\
\text { Schulz } \\
\text { Siderúrgica } \\
\text { Nacional } \\
\text { Souza Cruz } \\
\text { Telemar } \\
\text { Telesp } \\
\text { Tim Participações } \\
\text { Tupy } \\
\text { Vivo Participações } \\
\text { Wetzel }\end{array}$ \\
\hline
\end{tabular}

Fonte: Dados da pesquisa.

Os dados utilizados na pesquisa foram o Patrimônio Líquido, a quantidade de ações listadas e suas cotações históricas. Ambos extraídos do banco de dados Economatica ${ }^{\circledR}$, considerados na data base de 31 de dezembro dos anos em estudo.

\subsection{Variável Intangibilidade}

Para estimar o nível de intangibilidade das empresas, foi necessário primeiramente, determinar o valor de mercado do Patrimônio Líquido, que é o produto da seguinte formulação:

PLM = Qtde de ações em circulação x preço de mercado das ações

Apesar de limitações, esta fórmula é defendida por muitos autores, entre eles Damodaran (2007), Pratt e Grabowski (2008) e Brigham, Gapenski e Ehrhardt 
(2001) como sendo a mais objetiva. Também foi utilizada em diversas pesquisas, como as de Frezatti (1999) e Machado (2009).

Como foi necessário obter as cotações das ações para estimar o nível de intangibilidade, optou-se por calcular a média de intangibilidade das companhias ao longo de 6 anos, de 2002 a 2007. Isto diminuiu as distorções provocadas por diferentes momentos no mercado acionário, o que poderia gerar conclusões momentâneas e equivocadas.

Determinado o valor de mercado do Patrimônio Líquido, foi possível adotar como proxy de intangibilidade (Intang) das empresas, o índice Valor de Mercado/Valor Contábil:

$$
\text { Intang }=\frac{\mathrm{PL}_{\mathrm{M}}}{\mathrm{PL}_{\mathrm{C}}}
$$

Sendo:

$\mathrm{PL}_{\mathrm{M}}=$ Patrimônio Líquido ao valor de mercado;

$\mathrm{PL}_{\mathrm{C}}=$ Patrimônio Líquido ao valor contábil.

A proxy adotada é uma alternativa ao $\mathrm{Q}$ de Tobin, pois o cálculo deste último depara-se diante de dificuldades de acesso aos dados necessários, como o valor de mercado das dívidas e valor de reposição de ativos.

O índice Valor de Mercado/Valor Contábil pode ser utilizado baseando-se na estreita relação que os ativos intangíveis possuem com a parcela do valor de mercado da empresa que supera o valor contábil (HOSS; ROJO; GRAPEGGIA, 2010). Este indicador de intangibilidade também foi utilizado por Lev (2001) e Kayo e Famá (2004). Conforme o resultado do índice, os autores afirmam que as empresas podem ser tangível-intensivas e intangível-intensivas. Quanto maior o resultado, maior é a participação dos ativos intangíveis no valor das empresas.

\section{Análise dos Dados}

Antes de efetuar a estatística descritiva, em cada nível de governança, foi feito um corte para descartar os outliers. Após o cálculo do escore padronizado, foram classificados como outliers os indicadores que apresentaram escores maiores do que 3. Esse procedimento teve o intuito de obter dados mais consistentes e melhorar a análise estatística. Com isto, o estudo foi efetuado com 312 observações, sendo 52 empresas durante 6 anos.

Feito o descarte dos outliers, efetuou-se a estatística descritiva em cada nível de governança. Os resultados encontram-se nas Tabelas 1 a 4: 
Tabela 1 - Estatística descritiva do Cluster 1 - Novo Mercado

\begin{tabular}{|c|c|c|c|c|c|c|c|c|c|}
\hline Período & $\begin{array}{c}1^{\text {o }} \\
\text { quartil }\end{array}$ & Média & $\begin{array}{c}3^{\text {o }} \\
\text { quartil }\end{array}$ & Mediana & $\begin{array}{c}\text { Desvio- } \\
\text { padrão }\end{array}$ & Variância & Mínimo & Máximo & $\mathrm{N}$ \\
\hline 2002 & 0,24 & 1,25 & 0,96 & 0,54 & 2,0239 & 4,0962 & 0,13 & 6,75 & 10 \\
\hline 2003 & 0,41 & 2,01 & 1,93 & 0,93 & 2,5799 & 6,6559 & 0,61 & 8,11 & 10 \\
\hline 2004 & 0,29 & 1,85 & 1,85 & 0,89 & 2,3256 & 5,4085 & 0,21 & 6,34 & 10 \\
\hline 2005 & 0,72 & 3,75 & 1,30 & 1,11 & 0,6028 & 0,3634 & 0,52 & 1,31 & 10 \\
\hline 2006 & 1,30 & 2,89 & 2,82 & 2,12 & 2,3154 & 5,3610 & 0,92 & 7,39 & 10 \\
\hline 2007 & 2,28 & 3,86 & 5,89 & 2,85 & 2,7035 & 7,3088 & 0,95 & 7,50 & 10 \\
\hline $\begin{array}{c}2002 \mathrm{a} \\
2007\end{array}$ & 2,24 & 3,54 & 4,34 & 2,79 & 2,5600 & 6,5700 & 0,65 & 7,29 & 10 \\
\hline
\end{tabular}

Fonte: Dados da pesquisa.

Tabela 2 - Estatística descritiva do Cluster 2 - Nível 2

\begin{tabular}{|c|c|c|c|c|c|c|c|c|c|}
\hline Período & $\begin{array}{c}1^{\mathbf{o}} \\
\text { quartil }\end{array}$ & Média & $\begin{array}{c}3^{\text {o }} \\
\text { quartil }\end{array}$ & Mediana & $\begin{array}{c}\text { Desvio- } \\
\text { padrão }\end{array}$ & Variância & Mínimo & Máximo & $\mathrm{N}$ \\
\hline 2002 & 0,84 & 1,71 & 2,30 & 1,14 & 1,5421 & 2,3781 & 0,54 & 3,46 & 4 \\
\hline 2003 & 0,93 & 1,19 & 1,51 & 1,30 & 0,5873 & 0,3449 & 0,56 & 1,72 & 4 \\
\hline 2004 & 1,13 & 1,39 & 1,71 & 1,52 & 0,5903 & 0,3484 & 0,75 & 1,91 & 4 \\
\hline 2005 & 1,23 & 1,52 & 1,95 & 1,82 & 0,7654 & 0,5859 & 0,65 & 2,09 & 4 \\
\hline 2006 & 1,69 & 2,24 & 2,80 & 2,28 & 1,1105 & 1,2333 & 1,11 & 3,33 & 4 \\
\hline 2007 & 1,95 & 2,42 & 3,00 & 2,65 & 1,0638 & 1,1317 & 1,26 & 3,34 & 4 \\
\hline $\begin{array}{c}2002 \mathrm{a} \\
2007\end{array}$ & 1,33 & 1,81 & 2,16 & 1,68 & 0,6471 & 0,4187 & 1,24 & 2,64 & 4 \\
\hline
\end{tabular}

Fonte: Dados da pesquisa.

Tabela 3 - Estatística descritiva do Cluster 3 - Nível 1

\begin{tabular}{|c|c|c|c|c|c|c|c|c|c|}
\hline Período & $\begin{array}{c}1^{\mathbf{0}} \\
\text { quartil }\end{array}$ & Média & $\begin{array}{c}3^{\text {o }} \\
\text { quartil }\end{array}$ & Mediana & $\begin{array}{c}\text { Desvio- } \\
\text { padrão }\end{array}$ & Variância & Mínimo & Máximo & $\mathrm{N}$ \\
\hline 2002 & 0,20 & 0,86 & 0,79 & 0,44 & 1,1980 & 1,4353 & 0,17 & 4,26 & 15 \\
\hline 2003 & 0,39 & 1,02 & 1,18 & 0,67 & 1,0085 & 1,0170 & 0,23 & 4,15 & 15 \\
\hline 2004 & 0,64 & 1,43 & 1,57 & 1,07 & 1,2120 & 1,4689 & 0,29 & 4,52 & 15 \\
\hline 2005 & 1,04 & 1,46 & 1,40 & 1,26 & 1,0020 & 1,0040 & 0,28 & 4,37 & 15 \\
\hline 2006 & 1,17 & 1,82 & 2,34 & 1,69 & 0,8728 & 0,7618 & 0,35 & 3,70 & 15 \\
\hline 2007 & 1,37 & 2,21 & 2,85 & 1,99 & 1,2079 & 1,4591 & 0,35 & 4,74 & 15 \\
\hline $\begin{array}{c}2002 \mathrm{a} \\
2007\end{array}$ & 1,03 & 1,64 & 1,82 & 1,36 & 1,0445 & 1,0911 & 0,29 & 4,08 & 15 \\
\hline
\end{tabular}

Fonte: Dados da pesquisa.

Tabela 4 - Estatística descritiva Cluster 4 - Sem Adesão

\begin{tabular}{|c|c|c|c|c|c|c|c|c|c|}
\hline Período & $\begin{array}{c}1^{\mathbf{0}} \\
\text { quartil }\end{array}$ & Média & $\begin{array}{c}3^{\mathbf{0}} \\
\text { quartil }\end{array}$ & Mediana & $\begin{array}{c}\text { Desvio- } \\
\text { padrão }\end{array}$ & Variância & Mínimo & Máximo & $\mathrm{N}$ \\
\hline 2002 & 0,37 & 1,08 & 1,62 & 0,76 & 1,3173 & 1,7354 & 0,1 & 3,97 & 23 \\
\hline 2003 & 0,38 & 1,75 & 2,21 & 1,09 & 2,8961 & 8,3873 & 0,16 & 5,64 & 23 \\
\hline 2004 & 0,48 & 2,84 & 3,30 & 1,51 & 4,3768 & 18,857 & 0,17 & 6,26 & 23 \\
\hline 2005 & 0,82 & 2,54 & 2,41 & 1,45 & 4,0205 & 16,165 & 0,59 & 5,07 & 23 \\
\hline 2006 & 0,80 & 2,75 & 2,84 & 1,85 & 5,6307 & 31,704 & 0,66 & 7,05 & 23 \\
\hline 2007 & 0,90 & 1,45 & 2,84 & 2,09 & 3,8645 & 14,934 & 0,81 & 5,29 & 23 \\
\hline $\begin{array}{c}2002 \text { a } \\
2007\end{array}$ & 1,00 & 2,06 & 3,41 & 1,70 & 2,0699 & 4,2843 & 0,65 & 5,89 & 23 \\
\hline
\end{tabular}

Fonte: Dados da pesquisa. 
Observa-se que as menores variações ocorreram no Nível 2 e Nível 1, constantes na Tabela 2 e Tabela 3 respectivamente. Nestes dois grupos, as diferenças entre médias e medianas foram pequenas, assim como o desvio-padrão. $\mathrm{O}$ nível de intangibilidade apresentado também é muito próximo: $\mu$ Intang N2 $=1,81$, e $\mu$ Intang $\mathrm{N} 1=1,64$. Isto sugere que as diferenças entre as práticas de governança exigidas por estes dois segmentos não são suficientes para influenciar significativamente a geração de ativos intangíveis.

Os grupos que apresentaram maior variabilidade nos resultados, conforme as Tabelas 1 e 4, foram o Novo Mercado e Sem Adesão, respectivamente. Ambos apresentaram maior desvio-padrão, sendo respectivamente $\sigma \mathrm{NM}=2,5600$ e $\sigma \mathrm{SA}$ $=2,0699$, os quais podem ser verificados pela distancia que mínimos e máximos apresentam em relação à média. As diferenças entre médias e medianas também foram as maiores entre os grupos. Esta variabilidade demonstra que existe maior disparidade no nível de intangibilidade entre as empresas de ambos os grupos.

O segmento que exige práticas mais rígidas de governança, Novo Mercado, foi aquele que apresentou maior intangibilidade média no período estudado: $\mu$ Intang $\mathrm{NM}=3,54$. Analisando ano a ano, este grupo apresentou o maior nível em quatro, dos seis anos estudados. Por mais que não seja confiante efetuar uma comparação de apenas um ano, o fato de este grupo não ter apresentado a maior média de intangibilidade nos anos 2002 e 2004 demonstra que existem outros fatores importantes que influenciam o nível de intangibilidade das empresas. Nestes dois anos, o grupo de maior intangibilidade foi, respectivamente, Nível 2 e Sem Adesão.

O grupo de empresas Sem Adesão apresentou alta intangibilidade média, $\mu$ Intang $\mathrm{SA}=2,06$, tendo superado o Nível 2 e Nível 1, exceto nos anos de 2002 e 2007. Porém, é necessário ressaltar o elevado desvio-padrão, assim como no Novo Mercado.

Nota-se uma ordem de intangibilidade média no período estudado: o cluster 1 apresentou maior média, seguido pelo cluster 4 e finalmente, os clusters 2 e 3 . Este resultado impossibilitou, até o momento, a validação da hipótese traçada.

Efetuada a estatística descritiva, foi aplicado o teste t-Student para comparar o nível médio de intangibilidade entre os grupos e testar, de modo mais convincente, a hipótese da pesquisa. Para analisar a precisão na inferência realizada foi calculado o intervalo de confiança das médias. Ambos foram efetuados considerando o nível de significância $(\alpha)$ de $5 \%$, como risco do erro da inferência estatística. Os graus de liberdade foram considerados como $\varphi=n-1$. Os resultados encontram-se na Tabela 5: 
Tabela 5 - Resultados t-Student e Intervalo de Confiança

\begin{tabular}{|l|c|c|c|}
\hline & $\begin{array}{c}\text { Graus de } \\
\text { Liberdade }(\boldsymbol{\varphi})\end{array}$ & $\begin{array}{c}\text { Distribuição } \\
(\boldsymbol{t})\end{array}$ & $\begin{array}{c}\text { Intervalo de } \\
\text { Confiança }(\boldsymbol{P})\end{array}$ \\
\hline Cluster 1 & 9 & 1,8331 & 1,$38 ; 4,35$ \\
\hline Cluster 2 & 3 & 2,3534 & 0,$13 ; 1,55$ \\
\hline Cluster 3 & 15 & 1,7613 & 0,$22 ; 1,10$ \\
\hline Cluster 4 & 22 & 1,7171 & 0,$37 ; 1,63$ \\
\hline
\end{tabular}

Fonte: Dados da pesquisa.

Observa-se pelos resultados dos intervalos de confiança, que os clusters 2 e 3, representados por Nível 2 e Nível 1 respectivamente, apresentam um maior grau de precisão na inferência realizada. Conforme demonstrado na estatística descritiva, estes foram os grupos que apresentaram menor variabilidade, representada pelo baixo desvio-padrão, principalmente o cluster 3. É possível notar que não há grande diferença no nível de intangibilidade entre estes dois grupos, mas é preciso ressaltar que o cluster 2 apresenta possibilidade de maior nível de intangibilidade, através do intervalo $\mathrm{PN} 2=0,13 ; 1,55$, comparando-se ao cluster 3 , com intervalo $\mathrm{PN} 1=0,22 ; 1,10$.

Por outro lado, os clusters 1 e 4 apresentaram intervalos maiores, notoriamente o cluster 1, explicando novamente o elevado desvio-padrão deste grupo. O resultado estatístico sugere que as empresas constantes no Novo Mercado apresentam o nível médio de intangibilidade em torno de $\mathrm{PNM}=1,38$ a 4,35, com $95 \%$ de confiança, reforçando novamente a maior média de intangibilidade deste grupo. Quanto ao cluster 4, seu intervalo demonstra que o nível médio de intangibilidade fica entre PSA $=0,37$ a 1,63 em 95\% dos casos. O intervalo que demonstra os níveis mínimos e máximos de intangibilidade média deste cluster supera os clusters 2 e 3 .

De acordo com os resultados encontrados não foi possível validar a hipótese de que o nível médio de intangibilidade das empresas brasileiras de capital aberto acompanha os segmentos diferenciados de Governança Corporativa. Por um lado, o cluster 1, formado pelas companhias do Novo Mercado, segmento de maior exigência de praticas de governança, apresentou a maior média de intangibilidade no período estudado. O calculo do intervalo de confiança para este grupo, demonstrou que este apresenta possibilidade de maior intangibilidade em relação aos demais. Porém, o cluster 4, formado pelas companhias Sem Adesão, apresentou maior média de intangibilidade do que aquelas que compõe os clusters 2 e 3 , formados pelas companhias que aderem ao Nível 2 e Nível 1 respectivamente. O intervalo de confiança desses dois clusters demonstraram possibilidade de um menor nível médio de intangibilidade em relação ao cluster 4.

$\mathrm{O}$ fato de os resultados não validarem a hipótese estabelecida sugere, 
como prega a literatura, que existem outros fatores fortemente geradores de ativos intangíveis. Por mais que uma companhia tenha preocupação em implantar boas práticas de governança, ela pode estar pecando na gestão dos demais elementos, provocando um efeito de compensação. Surge então a possibilidade de pesquisas futuras na tentativa de descobrir estes fatores e sua magnitude de influencia na geração de ativos intangíveis.

Alguns resultados encontrados no presente trabalho corroboram as seguintes pesquisas:

- Silva e Leal (2005): as companhias com boas práticas de governança têm um desempenho econômico e valor superiores às demais;

- Terra e Lima (2006): os investidores reagem de forma diferenciada a alguns sinalizadores de boas práticas de governança, fazendo então, aumentar o valor de mercado da empresa;

- Lameira, Ness Junior e Soares (2007): a melhoria de práticas de governança corporativa promove impacto no valor das companhias aberta; e

- Monte e outros (2010): o nível mais elevado de práticas de governança produz impacto no valor das empresas.

Se os Níveis Diferenciados de Governança Corporativa influenciam o valor de mercado das empresas, o mesmo é verdade para os ativos intangíveis. Isto porque, o aumento do valor de mercado conduz a um maior resultado do índice PLM/PLC, denotando maior participação de ativos intangíveis na estrutura das empresas.

Outro resultado confirmado diz respeito a baixa diferença de intangibilidade entre as empresas dos níveis 2 e 1 , o que vai de encontro com as pesquisas de Lameira, Ness Junior e Soares (2007) e Monte e outros (2010). Estes autores demonstraram que as diferenças de exigências para acesso a estes níveis não são relacionados com valor.

\subsection{Limitações}

Mesmo baseando-se em teorias de apoio e pesquisas recentes, e ainda tendo efetuado cálculos estatísticos para atingir melhores resultados, a pesquisa apresenta algumas limitações.

A análise restringiu-se a 55 companhias, por terem apresentado dados completos nos seis anos estudados. Assim, não é possível generalizar os resultados encontrados, já que amostras não probabilísticas não garantem a representatividade da população.

Podem haver diferenças de práticas contábeis entre as companhias, fazendo com que os valores de Patrimônio Líquido sejam alterados, não por implantação 
de melhores práticas de gestão, mas sim, por alterações em políticas contábeis.

Os preços das ações são influenciados por diversos fatores, assim, a consideração da resposta do mercado acionário deve ser tomada com cuidado ao avaliar a geração de ativos intangíveis. A pesquisa tentou minimizar este problema, ao considerar uma média de 6 anos, mas não é o suficiente para excluir o problema inteiramente.

Por fim, é necessário afirmar que, mesmo havendo evidências parciais de influencia de práticas de governança no nível de intangibilidade das empresas, é difícil avaliar exatamente a parcela do ativo intangível proveniente de boas práticas de Governança Corporativa.

\section{Considerações Finais}

O objetivo do trabalho foi verificar, através de um estudo exploratóriodescritivo, se o nível médio de intangibilidade das empresas brasileiras de capital aberto acompanha os Níveis Diferenciados de Governança Corporativa ao qual submetem-se.

Delimitado o problema, a hipótese a ser verificada e o objetivo, foi descrito o referencial teórico, baseando-se nas principais referencias sobre o tema. Também foram descritas pesquisas recentes, servindo de evidencias para comparações e interpretações dos dados aqui encontrados.

$\mathrm{Na}$ metodologia foi calculado o índice de intangibilidade para as empresas da amostra, agrupadas conforme o segmento de governança ao qual aderem. Como ferramenta quantitativa, utilizou-se, além da estatística descritiva, a distribuição t-Student e os intervalos de confiança.

De posse dos resultados não foi possível validar a hipótese levantada. O nível mais rígido de governança, Novo Mercado, apresentou maior média de intangibilidade no período estudado. Porém, os demais segmentos, Nível 2 e Nível 1, apresentaram um nível médio de intangibilidade menor do que o grupo de empresas sem adesão às práticas diferenciadas.

As práticas de Governança Corporativa agregam valor as sociedades por proporcionar mecanismos mais efetivos para consolidar negócios competitivos, elevando o nível de confiança dos acionistas. Assim, é lógico afirmar que Governança Corporativa contribui com a geração de Ativo Intangível, porém, conforme demonstrado na presente pesquisa, é difícil encontrar uma relação direta entre ambas as variáveis.

Por fim, sugere-se como pesquisas futuras, utilizar variáveis específicas das empresas, como tamanho, crescimento e rentabilidade, para que sejam analisadas as correlações com o nível de intangibilidade. A utilização de outras variáveis de governança, como origem e dispersão do capital, divulgação voluntária e rodízio 
entre membros de conselhos de administração e fiscal pode também prover resultados relevantes. E ainda, podem ser dedicados maiores esforços na tentativa de minimizar as limitações desta pesquisa, descritas ao fim do desenvolvimento metodológico. Estes esforços podem ser direcionados no sentido de contribuir com o mercado de capitais brasileiro, o qual tem apresentado desenvolvimento notório nos últimos anos.

Os Ativos Intangíveis e Governança Corporativa são conseqüência do desenvolvimento da economia de mercado e das sociedades capitalistas. Empresas que dimensionam esforços para a boa gestão desses dois elementos, apresentam um forte potencial para o crescimento sustentado.

\section{Referências}

ANDRADE, A.; ROSSETTI, J. P. Governança Corporativa. Fundamentos, Desenvolvimento e Tendências. 4. ed. São Paulo: Atlas, 2009.

BERTUCCI, J. L. O.; BERNARDES, P.; BRANDÃO, M. M. Políticas e práticas de governança corporativa em empresas brasileiras de capital aberto. Revista de Administração. São Paulo, v. 41, n. 2, p. 183-196, abr/jun. 2006.

BM\&FBOVESPA. Bolsa de Valores Mercadorias e Futuros de São Paulo. Disponível em: <http://www.bmfbovespa.com.br> Acesso em: 15 out. 2010.

BRIGHAM, E. F.; GAPENSKI, L. C.; EHRHARDT, M. C. Administração Financeira. Teoria e Prática. São Paulo: Atlas, 2001.

CANNING, J. B. The economics of accountancy. New York: Ronald Press, 1929.

DAMODARAN, A. Avaliação de Empresas. 2. ed. São Paulo: Pearson, 2007.

FREZATTI, F. A decomposição do MVA® (Market Value Added) na análise de valor da empresa. Revista de Administração, São Paulo, v. 34, n. 3, p. 32-43, jul./ set. 1999.

GONÇALVES, R. S., WEFFORT, E. F. J., PELEIAS, I. R., GONÇALVES, A. O. Social Disclosure das Empresas Brasileiras Listadas na NYSE e na BOVESPA sua relação com os níveis de governança corporativa. Revista Contemporânea de Contabilidade. Florianópolis, v. 1, n.9, p. 71-94, jan./jun., 2008.

HENDRIKSEN, E. S.; VAN BREDA, M. F. Teoria da contabilidade. São Paulo: Atlas, 1999. 
HOSS, O.; ROJO C. A.; GRAPEGGIA, M. Gestão de ativos intangíveis. Da mensuração à competitividade por cenários. São Paulo: Atlas, 2010.

IBGC. Instituto Brasileiro de Governança Corporativa. Disponível em: $<$ http:// www.ibgc.org.br/home.asp>. Acesso em: 30 out. 2010.

IUDÍCIBUS, S.; LOPES, A. B. Coord. Teoria Avançada da Contabilidade. São Paulo: Atlas, 2004.

IUDÍCIBUS, S. Teoria da Contabilidade. 7. ed. São Paulo: Atlas, 2004.

JENSEN, M. C.; MECKLING, W. H. Theory of the firm: managerial behavior, agency costs and ownership structure. Journal of Financial Economics, Amsterdam, v. 3, n. 4, p. 305-360, Oct. 1976.

JESUS, S. M., ALBERTON, L. O Processo de Implementação da Governança Corporativa nas Empresas de Capital Aberto: Um Estudo com Ênfase na Auditoria. Revista Contemporânea de Contabilidade. Florianópolis, v. 1, n.8, pg. 67-84, jan./jun., 2007.

KAM, V. Accounting theory. 2. ed. Nova Iorque: Wiley, 1990.

KAYO, E. K. A estrutura de capital e o risco das empresas tangível e intangívelintensivas: uma contribuição ao estudo da valoração de empresas. Tese (Doutorado em Administração). Faculdade de Economia e Administração. São Paulo. 2002.

KAYO, E. K.; TEH, C. C.; BASSO, L. F. C. Ativos intangíveis e estrutura de capital: a influência das marcas e patentes sobre o endividamento. Revista de Administração, São Paulo: v.41, n.2, p. 158-168, abr./jun. 2006.

LAMEIRA, V. de J.; NESS JUNIOR W. L.; SOARES, T. D. L. V. A. M. Governança corporativa: impactos no valor das companhias abertas brasileiras. Revista de Administração. São Paulo, v. 42, n.1, p. 64-73, jan/mar. 2007.

LEV, B. Intangibles: management and reporting. Washington: Brookings, 2001.

MACHADO, J. H. Custo de Capital Ponderado a Valor de Mercado: Análise de sua Influência na Determinação do Valor Econômico Agregado. Revista Brasileira de Contabilidade, Brasília, n. 175, p. 71-81, jan/fev. 2009.

MALACRIDA, M. J. C.; YAMAMOTO, M. M. Governança corporativa: nível de evidenciação das informações e sua relação com a volatilidade das ações do Ibovespa. Revista de Contabilidade e Finanças. São Paulo. Edição comemorativa, p. 65-79. set. 2006. 
MARTINS, E. Contribuição à avaliação do ativo intangível. Tese (Doutorado em Contabilidade). Faculdade de Economia e Administração. São Paulo. 1972.

MONTE, P. A. e outros. Existe relação entre Governança Corporativa e a volatilidade? Um estudo a partir da formação de carteiras. Revista Contabilidade Vista \& Revista. Belo Horizonte, v. 21, n. 2, p. 15-44, abr/jun. 2010.

MONTGOMERY, C. A.; KAUFMAN, R. The board's missing link. Harvard Business Review, Boston, v. 80, n. 3, Mar. 2003.

PEREZ, M. M.; FAMÁ, R. Ativos intangíveis e o desempenho empresarial. Revista de Contabilidade e Finanças. São Paulo, n. 40, p. 7-24, jan/abr. 2006.

PRATT, S. P.; GRABOWSKI, R. J. Cost of capital: Applications and Examples. 3. ed. Nova Jersey: Wiley, 2008.

SANTANA, M. H. O novo mercado e a governança corporativa. Revista da CVM, São Paulo, p. 4-8, dez. 2001.

SILVA, A. L. C.; LEAL, R. P. C. Índice de Governança Corporativa, Valor e Desempenho da Firma no Brasil. Revista Brasileiras de Finanças, São Paulo, v. 3, n. 1, p. 1-18, 2005.

SILVA, A. L. C. Governança Corporativa, Valor, Alavancagem e Política de Dividendos das Empresas Brasileiras. Revista de Administração. São Paulo, v. 39, n. 4, p. 348-361, 2004.

TERRA, P. R. S.; LIMA, J. B. N. Governança corporativa e a reação do mercado de capitais a divulgação das informações contábeis. Revista de Contabilidade e Finanças. São Paulo, n. 42, p. 35-49, set/dez. 2006. 
